\title{
Prevalence of depression symptoms among Tibetan Buddhist monastic science scholars in India
}

\section{Jennifer Mascaro ( $\boldsymbol{\sigma}$ jmascar@emory.edu )}

Emory University School of Medicine https://orcid.org/0000-0002-6199-8455

\section{Danielle Shellman}

Emory University School of Medicine

\section{Tsondue Samphel}

Emory University

\section{Hope Chang}

Emory University School of Medicine

\section{Joel Zivot}

Emory University School of Medicine

\section{Arri Eisen}

Emory University

\section{Research article}

Keywords: Depression, PHQ-9, Tibetan, Buddhist, Monastic, Refugee mental health

Posted Date: July 14th, 2020

DOl: https://doi.org/10.21203/rs.3.rs-38653/v1

License: (c) (i) This work is licensed under a Creative Commons Attribution 4.0 International License. Read Full License 


\section{Abstract \\ Background}

Depression is the largest contributing factor to global disability, and the translation and validation of depression screening instruments is vital toward understanding the prevalence of depression symptoms around the world. The aim of this study was to translate a widely used depression screening instrument, the Patient Health Questionnaire (PHQ), for use with Tibetan populations, and to explore the prevalence of depression symptoms in a population of Tibetan-speaking Buddhist monastic science scholars.

\section{Methods}

A total of 384 monastics (363 monks, 21 nuns) completed the Tibetan PHQ-9. We computed measures of internal consistency and conducted factor analysis to evaluate scale performance, and describe the prevalence of depression symptoms among the monastic population and subgroups.

\section{Results}

The Tibetan PHQ-9 had acceptable reliability and demonstrated a single-factor structure. While having low energy was the most commonly endorsed symptom, monastics did not have overall higher rates of other somatic symptoms. Over $10 \%$ of the monastics scored in the moderately severe to severe range, using standard diagnostic criteria cut-offs. First year monks had the highest mean score, and there was not a significant difference between monks and nuns.

\section{Conclusion}

These preliminary findings indicate that the Tibetan PHQ-9 is a reliable instrument for exploring and assessing depression symptoms and that it will be useful toward examining how symptoms are experience, interpreted, and communicated among Buddhist monastics.

\section{Background}

Over 350 million people worldwide suffer from depression, making it the most common mental health disorder and the largest contributing factor to global disability (1-4). Typified by persistent sadness and a lack of interest or pleasure in previously rewarding activities, the causes of depression are multifactorial just as the effects can be both wide-ranging and long-lasting. Given its global impact and burden of suffering, it is critical to understand the cross-cultural variance in depression symptoms, as well as the factors that impact depression symptoms across time and place. Vital to this understanding are diagnostic screening instruments that are adapted and validated for use among diverse populations. 
There are an estimated 150,000 Tibetan refugees living in exile, having left Tibet due to political and cultural oppression (5). Previous work has documented elevated levels of trauma, post-traumatic stress disorder, and anxiety among these Tibetan humanitarian migrants (6). Tibetan exile began in 1959 with the escape of the 14th Dalai Lama to India to avoid persecution by the Chinese People's Liberation Army (7). While Tibetan refugees still travel to Dharamsala - the current residence of the Dalai Lama in India the number has dropped over the last decade, due in part to economic and cultural uncertainty in India (8). Many Tibetans from both Tibet and India are traveling to other countries, such as Canada and Germany (8). With this history of persecution and oppression and elevated risk for mental health concerns, and given the dynamic insecurities experienced by Tibetans living in diaspora communities, it is crucial to translate, adapt, and examine psychometric instruments for screening depression among Tibetans and Tibetans in exile.

Among the almost 40,000 Tibetan Buddhist monastics living in India and nearby countries (9), a growing number participate in a novel science curriculum, the Emory-Tibet Science Initiative (ETSI). First created in 2006 at the behest of His Holiness the Dalai Lama, ETSI is a collaboration between Emory University and the Library of Tibetan Works and Archives to establish a bidirectional convergence of science and spirituality. The program aims to innovate and implement a comprehensive and rigorous educational curriculum built on shared systems of knowledge to teach contemporary scientific knowledge to Tibetan monks and nuns. Science faculty collaborate with Tibetan translators and teachers to provide continuous English-Tibetan translation during classes. As of 2018 , over 1,000 monastics engaged with what is now a 6-year ETSI science curriculum in neuroscience, biology, physics, and epistemology, which includes a summer science intensive program (10). Beginning in 2018, scientific concepts taught during ETSI are now included in the Gelug Geshe exam, the monastic equivalent to a PhD qualifying exam.

In addition to the importance of constructing diagnostic tools for screening depression in Tibetan communities, exploring depressive symptoms among Tibetan Buddhist monastics presents an opportunity to understand the proximate outcome of the complex interaction of factors that enact both risk for and buffering against depression. On the one hand, growing research highlights the deleterious impact to mental health that can result from becoming a humanitarian migrant $(11,12)$. On the other hand, many monastics maintain a lifestyle that may buffer them from developing depression. For example, the interconnected community of a monastery likely reduces loneliness and economic stress, both of which increase the risk for mental illness during post-migration resettlement $(11,13)$. Monastics often primarily consume a vegetarian diet, which has been associated with a reduced prevalence of depression (14). Moreover, some - though not all - Tibetan Buddhist monastics maintain regular contemplative practices, which have positive effects on mental health and well-being (15). In addition to practices, Buddhist belief systems may buffer monastics from the harmful effects of stress or trauma, and may provide a mental framework that shapes symptoms of depression and mental distress (16-18). In sum, the monastic lived experience includes both risk and buffering factors, and examining mental health and illness in this context will enrich our overall understanding. 
In this study, we examined the prevalence of depression symptoms among ETSI scholars. Toward this goal, our first aim was to translate one of the most widely used depression screening instruments (19), the Patient Health Questionnaire (PHQ), for use with Tibetan populations. Our second aim was to use the Tibetan PHQ-9 (T-PHQ-9) to explore the prevalence of depression symptoms in a population of Tibetanspeaking Buddhist monks and nuns enrolled in ETSI.

\section{li. Methods}

Study Design: The Emory University Institutional Review Board approved the study, and all work was carried out in accordance with the Declaration of Helsinki. We obtained signed, informed consent from 453 monastic participants (419 monks, 34 nuns) after a full description (in Tibetan) of study procedures and risks and potential benefits, and prior to conducting any study procedures.

Participants: Participants in the quantitative study were Tibetan monastics who reside in the Tibetan monastic community in India and who attend classes to study science with the Emory-Tibet Science Initiative (ETSI), held at the Science Center at the Drepung Losel Ling Monastery in South India.

Monastics were from four monasteries and five nunneries engaged with the ETSI program and located in the Tibetan exile communities of India. We recruited monastics via an optional face-to-face presentation. There were no exclusion criteria. Because we were interested in item performance, we omitted participants who were missing items $(n=69)$ and thus the final dataset was composed of 384 monastics (363 monks, 21 nuns).

Measure: The Patient Health Questionnaire depression module (PHQ-9) is a measure of depression severity that scores each of nine Diagnostic and Statistical Manual of Mental Disorders symptom criteria according to how often the symptom bothered the person during the previous 2 weeks: " 0 " (not at all) to " 3 " (nearly every day) (20). The nine symptoms assessed are (1) anhedonia, (2) depressed mood, (3) insomnia or hypersomnia, (4) fatigue or loss of energy, (5) appetite disturbances, (6) guilt, (7) diminished ability to think or concentrate, (8) psychomotor agitation, and (9) suicidal ideation. A tenth item rates how the depression symptoms impact daily function, but it is not used in scoring and is not included here. We used conventional categories of symptom severity: Minimal depression severity, 0-4; Mild, 5-9; Moderate, 10-14; Moderately severe, 15-19; Severe, 20-27 (21).

Measure translation: In the first phase, one translator proficient in English and Tibetan translated the PHQ-9 into Tibetan. Translation and back translation of the Tibetan version of the PHQ-9 was repeated by a group of 5 translators until they believed that the Tibetan version corresponded faithfully with the English version.

The T-PHQ-9 was printed on a single sheet of paper and administered to each monastic participant by a single research coordinator. Prior to administering the survey, the research coordinator explained the purpose of the study through an experienced English to Tibetan interpreter employed as an educator by ETSI. Monastics were informed that non-participation was an option without penalty or stigma and that if they chose to participate their surveys would be anonymous. Informed consent to participate in the study 
was obtained through verbal affirmation. After consent, monastics completed the survey with no time restrictions and they were able to ask questions of the research team via the translator. After completion of the survey, the research coordinator collected the paper copies and stored them securely and confidentially until the data could be entered.

Statistical Analysis: All data were double entered to ensure accuracy. Toward our first aim of evaluating individual T-PHQ-9 items and scale performance, we examined the internal consistency by computing the Cronbach's alpha coefficient. To evaluate construct validity, we conducted a factor analysis to evaluate whether a single factor model could be generated for the 9 items of the Tibetan PHQ-9, as has been reported in previous studies (e.g. (22-25)), or whether a two- or three-factor model was a better fit. First, we assessed whether the data were suitable for conducting a factor analysis and found that it was appropriate to proceed (Bartlett's test of sphericity $(p<0.001)$, and the Kaiser-Meyer-Olkin measure of sample adequacy $=0.83$ ). Next, we conducted a principal component analysis, excluding cases listwise.

To describe the prevalence of depression symptoms in the monastic population, we generated descriptive statistics (mean, standard deviation, and endorsement frequency) for single items and for the sum score of the measure. In addition, we describe monastic participants' scores according to PHQ-9 diagnostic categories, separated by year in the ETSI program and sex for comparison. To examine whether depression scores differed by ETSI year, we conducted one-way ANOVA followed by Games-Howell posthoc multiple comparisons tests. To examine whether scores differed between monks and nuns, we conducted a Mann-Whitney test.

\section{lii. Results}

Reliability and item analysis: Cronbach's alpha for the total scale was 0.71 , which is considered acceptable. The mean scores for all PHQ-9 items are shown in Table 1. All items, if deleted, would decrease the total alpha, although the alpha would be essentially the same if item 9 (suicidal ideation) were deleted. Item 9 also had the lowest item-total correlation and was endorsed far less frequently than all other items (see Tables 1 and 2). Item-total correlations ranged from 0.30 to 0.46 (Table 1). 
Table 1

T-PHQ-9 descriptive, reliability, and factor loading statistics

\begin{tabular}{|c|c|c|c|c|c|}
\hline & & & $\begin{array}{l}\text { Corrected item- } \\
\text { total correlation }\end{array}$ & & $\begin{array}{l}\text { Factor-pattern } \\
\text { coefficient }\end{array}$ \\
\hline & Mean & $\begin{array}{l}\text { Std. } \\
\text { Deviation }\end{array}$ & & $\begin{array}{l}\text { Alpha if } \\
\text { item } \\
\text { deleted }\end{array}$ & \\
\hline Anhedonia & 0.43 & 0.70 & 0.39 & 0.69 & 0.56 \\
\hline Depressed mood & 0.36 & 0.65 & 0.45 & 0.68 & 0.62 \\
\hline Sleep problems & 0.55 & 0.85 & 0.43 & 0.68 & 0.60 \\
\hline Low energy & 0.87 & 0.80 & 0.40 & 0.69 & 0.57 \\
\hline Appetite change & 0.38 & 0.69 & 0.35 & 0.70 & 0.51 \\
\hline Low self-esteem & 0.70 & 0.90 & 0.42 & 0.68 & 0.58 \\
\hline $\begin{array}{l}\text { Concentration } \\
\text { difficulties }\end{array}$ & 0.66 & 0.88 & 0.34 & 0.70 & 0.49 \\
\hline $\begin{array}{l}\text { Psychomotor agitation } \\
\text { or retardation }\end{array}$ & 0.42 & 0.73 & 0.46 & 0.68 & 0.63 \\
\hline Suicidal ideation & 0.06 & 0.37 & 0.30 & 0.71 & 0.45 \\
\hline
\end{tabular}


Table 2

T-PHQ-9 item responses listed as percent monastics endorsing each response option. Each of the items is scored with the following 4-point response options: 0 (not at all), 1 (several days), 2 (more than half the days), and 3 (nearly every day).

\begin{tabular}{|lllll|}
\hline & $\mathbf{0}$ & $\mathbf{1}$ & $\mathbf{2}$ & $\mathbf{3}$ \\
\hline Anhedonia & $\begin{array}{l}\text { "Not at } \\
\text { all" }\end{array}$ & $\begin{array}{l}\text { "Several } \\
\text { days" }\end{array}$ & $\begin{array}{l}\text { "More than half the } \\
\text { days" }\end{array}$ & $\begin{array}{l}\text { "Nearly every } \\
\text { day" }\end{array}$ \\
\hline Depressed mood & 68.0 & 22.7 & 8.1 & 1.3 \\
\hline Sleep problems & 71.9 & 20.8 & 6.3 & 1.0 \\
\hline Low energy & 64.6 & 20.3 & 10.9 & 4.2 \\
\hline Appetite change & 36.5 & 43.5 & 16.9 & 3.1 \\
\hline Low self-esteem & 71.6 & 20.6 & 5.7 & 2.1 \\
\hline $\begin{array}{l}\text { Concentration } \\
\text { difficulties }\end{array}$ & 54.7 & 26.0 & 14.1 & 5.2 \\
\hline Psychomotor agitation & $\mathbf{5 5 . 2}$ & 29.2 & 9.9 & 5.7 \\
\hline Suicidal ideation & 97.3 & 19.5 & 8.1 & 2.1 \\
\hline Mean (Std. Dev.) & $\mathbf{6 5 . 5}$ & $\mathbf{2 2 . 6 ( 1 0 . 5 )}$ & 9.00 (4.43) & 1.0 \\
\hline
\end{tabular}

Construct validity: A principal components factor analysis yielded a single-factor structure, which accounted for $31.1 \%$ of the variance in item responses and yielded a total eigenvalue of 2.80 . The factorpattern coefficients ranged from $0.45-0.63$ (Table 1).

Prevalence of symptoms and participant characteristics: The item response frequencies are detailed in Table 2 and visualized in Fig. 1. The majority of monastics chose "Not at all" for all items except "Low energy', for which the majority (43.5\%) chose "Several days". T-PHQ-9 sum scores are detailed in Table 3. 
Table 3

Mean score, standard deviation, and frequency of diagnostic categories, broken down according to monastic year for monks, for all monks, for nuns, and for all monastics combined (monks and nuns).

\begin{tabular}{|c|c|c|c|c|c|c|c|c|c|}
\hline & $\begin{array}{l}1 \text { st } \\
\text { year }\end{array}$ & $\begin{array}{l}\text { 2nd } \\
\text { year }\end{array}$ & $\begin{array}{l}\text { 3rd } \\
\text { year }\end{array}$ & $\begin{array}{l}\text { 4th } \\
\text { year }\end{array}$ & $\begin{array}{l}5 \text { th } \\
\text { year }\end{array}$ & $\begin{array}{l}\text { 6th } \\
\text { year }\end{array}$ & Nuns & $\begin{array}{l}\text { All } \\
\text { Monks }\end{array}$ & All \\
\hline & $\begin{array}{l}(\mathrm{N}= \\
97)\end{array}$ & $\begin{array}{l}(\mathrm{N}= \\
38)\end{array}$ & $\begin{array}{l}(N= \\
52)\end{array}$ & $\begin{array}{l}(\mathrm{N}= \\
52)\end{array}$ & $\begin{array}{l}(\mathrm{N}= \\
64)\end{array}$ & $\begin{array}{l}(\mathrm{N}= \\
60)\end{array}$ & $\begin{array}{l}(N= \\
21)\end{array}$ & $\begin{array}{l}(N= \\
363)\end{array}$ & $\begin{array}{l}(\mathrm{N}= \\
384)\end{array}$ \\
\hline & $\begin{array}{l}M \\
\text { (s.d) }\end{array}$ & $\begin{array}{l}M \\
\text { (s.d) }\end{array}$ & $\begin{array}{l}M \\
\text { (s.d) }\end{array}$ & $\begin{array}{l}M \\
\text { (s.d) }\end{array}$ & $\begin{array}{l}M \\
(s . d)\end{array}$ & $\begin{array}{l}M \\
\text { (s.d) }\end{array}$ & $\begin{array}{l}M \\
\text { (s.d) }\end{array}$ & $\begin{array}{l}M \\
\text { (s.d) }\end{array}$ & $\begin{array}{l}M \\
(s . d)\end{array}$ \\
\hline & $\begin{array}{l}5.99 \\
(3.44)\end{array}$ & $\begin{array}{l}4.32 \\
(3.95)\end{array}$ & $\begin{array}{l}4.90 \\
(4.20)\end{array}$ & $\begin{array}{l}3.56 \\
(3.11)\end{array}$ & $\begin{array}{l}3.30 \\
(3.04)\end{array}$ & $\begin{array}{l}3.65 \\
(3.46)\end{array}$ & $\begin{array}{l}4.05 \\
(4.64)\end{array}$ & $\begin{array}{l}4.45 \\
(3.64)\end{array}$ & $\begin{array}{l}4.43 \\
(3.70)\end{array}$ \\
\hline & $\mathrm{n}(\%)$ & $\mathrm{n}(\%)$ & $\mathrm{n}(\%)$ & $\mathrm{n}(\%)$ & n (\%) & $\mathrm{n}(\%)$ & n (\%) & $\mathrm{n}(\%)$ & $\mathrm{n}(\%)$ \\
\hline $\begin{array}{l}\text { Minimal, } 0- \\
4\end{array}$ & $\begin{array}{l}36 \\
(37.1)\end{array}$ & $\begin{array}{l}23 \\
(60.5)\end{array}$ & $\begin{array}{l}28 \\
(53.8)\end{array}$ & $\begin{array}{l}37 \\
(65.4)\end{array}$ & $\begin{array}{l}47 \\
(73.4)\end{array}$ & $\begin{array}{l}41 \\
(68.3)\end{array}$ & $\begin{array}{l}15 \\
(71.4)\end{array}$ & $\begin{array}{l}209 \\
(57.6)\end{array}$ & $\begin{array}{l}224 \\
(58.3)\end{array}$ \\
\hline Mild, 5-9 & $\begin{array}{l}46 \\
(47.4)\end{array}$ & $\begin{array}{l}9 \\
(23.7)\end{array}$ & $\begin{array}{l}18 \\
(34.6)\end{array}$ & $\begin{array}{l}16 \\
(30.8)\end{array}$ & $\begin{array}{l}13 \\
(20.3)\end{array}$ & $\begin{array}{l}15 \\
(25.0)\end{array}$ & $\begin{array}{l}2 \\
(9.50)\end{array}$ & $\begin{array}{l}117 \\
(32.2)\end{array}$ & $\begin{array}{l}119 \\
(31.0)\end{array}$ \\
\hline $\begin{array}{l}\text { Moderate, } \\
10-14\end{array}$ & $\begin{array}{l}14 \\
(14.4)\end{array}$ & $\begin{array}{l}5 \\
(13.2)\end{array}$ & $\begin{array}{l}4 \\
(7.70)\end{array}$ & $\begin{array}{l}1 \\
(1.90)\end{array}$ & $\begin{array}{l}3 \\
(4.70)\end{array}$ & $\begin{array}{l}4 \\
(6.20)\end{array}$ & $\begin{array}{l}3 \\
(14.3)\end{array}$ & $\begin{array}{l}31 \\
(8.50)\end{array}$ & $\begin{array}{l}34 \\
(8.90)\end{array}$ \\
\hline $\begin{array}{l}\text { Mod. severe, } \\
15-19\end{array}$ & $\begin{array}{l}1 \\
(1.00)\end{array}$ & $\begin{array}{l}1 \\
(2.60)\end{array}$ & $\begin{array}{l}1 \\
(1.90)\end{array}$ & $\begin{array}{l}1 \\
(1.90)\end{array}$ & $\begin{array}{l}1 \\
(1.60)\end{array}$ & 0 & $\begin{array}{l}1 \\
(4.80)\end{array}$ & $\begin{array}{l}5 \\
(1.40)\end{array}$ & $\begin{array}{l}6 \\
(1.60)\end{array}$ \\
\hline $\begin{array}{l}\text { Severe, } 20- \\
27\end{array}$ & 0 & 0 & $\begin{array}{l}1 \\
(1.90)\end{array}$ & 0 & 0 & 0 & 0 & $\begin{array}{l}1 \\
(0.30)\end{array}$ & $\begin{array}{l}1 \\
(0.30)\end{array}$ \\
\hline
\end{tabular}

Participant sum scores were non-normally distributed, with skewness of 1.08 (S.E. $=0.13$ ) and kurtosis of 1.14 (S.E. 0.25). The mean sum score for all monastics was 4.43 (Std. Dev. = 3.70). First year monks had the highest mean score $(M=5.99, S D=3.44)$, which was significantly higher than the mean score for other years $(F(6,377)=5.34, p<0.001)$. Post-hoc analyses using Games-Howell tests indicated that 1 st year monks reported higher levels of depression than monks in their 4th $(p=0.001)$, 5th $(p<0.001)$, and 6th $(p=0.001)$ years. There were no other significant differences between ETSI year among the monks. Neither was there a significant difference between the monks and nuns $(U=3185, p=0.20)$. Using diagnostic criteria from previous reports, 244 (58.3\%) monastics were in the minimal severity range (0-4), $119(31.0 \%)$ in the mild severity range (5-9), $34(8.90 \%)$ in the moderate severity range (10-14), 6 $(1.60 \%)$ in the moderately severe range $(15-19)$, and $1(0.30 \%)$ in the severe range $(20-27)$ (Table 3$)$.

\section{Iv. Discussion}

The Tibetan translation of the PHQ-9 will be important for screening and understanding the prevalence of depression symptoms among Tibetans and Tibetan refugees faced with dynamic globalization and economic and cultural insecurity. We demonstrate that the Tibetan PHQ-9 has acceptable reliability and holds promise as a clinical instrument. Our exploratory factor analysis indicates that the Tibetan PHQ-9 
has a single factor structure, as is consistent with many previous studies (22-25) While other studies have supported a two-factor model, corresponding to somatic (e.g. sleep, appetite, and fatigue items) and non-somatic or affective symptoms (e.g. mood, suicidal thought items) (26-29), our data do not support such a model. Although the Tibetan PHQ-9 used here demonstrates acceptable reliability, it appears to have a lower alpha than has been found in other studies, many of which have yielded alpha levels above 0.80 (e.g. $(20,22,25,30-32)$ ). The lower reliability may reflect something about the current translation, or it may reflect true differences in the way that symptoms are interpreted, experienced, or reported by this unique study population.

With respect to individual item performance, these data indicate that all items were important to the overall construct. However, there was variance in item endorsement. Consistent with other studies, very few monastics endorsed experiencing suicidal ideation (33). The most commonly endorsed item, on the other hand, was 'Low energy', and the majority of the monastics (> 60\%) reported experiencing this symptom at least several days per week. Several studies conducted among Asian populations have found higher rates of somatic symptoms (sleep problems, low energy, and appetite change) (for example, (33-36)). While, the monastics in this study only had relatively higher rates of endorsement of 'Low energy', they did not have higher rates of other somatic symptoms. Taken with the single-factor model identified with these data, this study is not consistent with the characterization of Asian racial/ethnic groups as more likely to experience somatic symptoms of depression and it highlights the importance of moving beyond simple east-west essentialism $(37,38)$.

While the PHQ-9 is among the most widely used measures of depression and it has proven important as a diagnostic screening tool in many disparate clinical contexts and among diverse populations, the diagnostic utility of the current translation will require further evaluation. Previous research has indicated that diagnostic cutoff scores of 10 are clinically meaningful and have high levels of sensitivity (88\%) and specificity (88\%), as individuals with major depression seldom score in that range. Scores of 15 or greater usually signify the presence of major depression. Scores in between that range, from 10-14, are associated with less diagnostic sensitivity $(20,39)$. We used these criteria to interpret the current data; however, future research should examine the diagnostic validity of the T-PHQ-9.

Responses in the current study indicate that $89.3 \%$ of monastics fall in the minimal and mild range for depression. Interestingly over $10 \%$ of the monastics fell in the moderate and above range, with $2 \%$ categorized as experiencing moderately severe or severe depression. Comparing these data to previous studies of nationally representative samples suggests that the monastics do not report demonstrably lower levels of depressive symptoms. The point prevalence rates for depression in an American sample of adults was recently estimated at $8.1 \%$ (40). For men in the sample, the prevalence was $5.5 \%$, compared to $10.4 \%$ for women. Another study estimated that $95 \%$ of Germans fall into the minimal and mild range, with fewer people falling in the moderate and high range than we found in the current sample (24). Prevalence rates among adults in Sweden are comparable to rates observed in the monastics in this study, with $10.8 \%$ reporting clinically significant depression (41). While clinical interpretations of these data warrant great caution, our preliminary findings indicate that the T-PHQ-9 is sensitive to variation in 
depression symptoms and that it appears to be operating similarly to other population studies that evaluate the point prevalence of depression.

Careful consideration, however, should be given to determining the most appropriate comparison groups to interpret the current data; the monastic science students may have more in common with other student populations than with a more general adult population. Within student populations, there appears to be a relatively large amount of variance in PHQ-9 scores. For example, in a study of Chinese medical students, the mean PHQ-9 score was 6.02 and $13.5 \%$ of respondents reporting moderate to severe depression (1027 range) (42). Similarly, a large study of South Korean medical students found that $13.7 \%$ of students scored in the moderate to severe range (43). A study of medical students in Cameroon found that $30.6 \%$ scored in the moderate to severe range (44). There also appears to be extensive variation in prevalence of depression among university students, with rates of depression ranging from 10-85\% (45). Depression levels in the current study were at the bottom-end of what is generally seen in studies of university and post-graduate students.

If rates of depression among Tibetan Buddhist monastics are similar to or higher than rates found in other populations, some thoughts are warranted as to what factors influence this effect. Several large studies point to factors that exert direct effects on risk of major depression, including income, sleep disorders, and chronic diseases (46). Other studies find associations between nutritional status, adiposity, and physical activity and rates of depression $(14,44,47)$. Monastics may experience lifestyle factors that put them more at risk for depression, a possibility that warrants further inquiry. Large bodies of research have found that education $(48,49)$ and religiosity $(50,51)$ are protective against depression, which would suggest that monastics may be relatively buffered from experiencing depression. However, another study of Tibetan refugees living in India found lower prevalence of depression and importantly found no association between monastic status or educational variables and depression levels (52). Taken together, it may be that some monastics in our study experience a suite of lifestyle risk factors that have a net negative impact on their well-being.

In addition to common risk factors associated with elevated risk for depression, monastics in our sample may experience specific burdens that impact their experience of depression symptoms. Tibetan culture and traditions, including the growth and development of Monastic universities serve the purpose of maintaining Tibetan culture in the hope of a future repatriation to the ancestral homeland. A community in diaspora navigates the present circumstance with great care. By definition, the aspirations of the community are to return, but the reality requires the laying down of a local foundation. As the years pass, all that may be known is the current reality, and the more settled in place, the weaker the claim becomes for repatriation. Diaspora communities' risk adverse mental health as a consequence of state impermanence (53).

\section{Limitations and future directions}

For several reasons, caution is warranted with diagnostic claims or interpretations of the current data. First, as stated above, we did not conduct any validity estimates within the current study. Future research 
should examine convergent validity of the T-PHQ-9 and other validated instruments, as well with clinical diagnostic methods. Second, we were not able to conduct any qualitative evaluations to explore how monastics understood and related to the translated items. In future research, we will conduct semistructured cognitive interviews with a different group of monastics enrolled in ETSI in order to examine the clarity and relevance of each item and to understand their cognitive process in answering each item (54). While we performed back-translation and had input from 5 experienced translators, linguistic and cultural differences will impact the way emotions are perceived and interpreted, as well as how distress and symptoms of distress are communicated (38). Related, the monastics are relatively unfamiliar with survey instruments like the PHQ, which may impact the way they thought about the items or answered the survey. The use of cognitive interviewing to understand the translation and understanding of language related to depression symptoms will yield important insights about cross-cultural variation in mental health symptoms.

Another important next step in this research is to examine how age and sex impact monastic depression symptoms. While we did not find a significant difference between monks and nuns, we may have been underpowered to examine whether well-described sex-differences in depression $(40,55)$ are also evident among this monastic population. Nuns are newly involved with ETSI, and as their representation grows there will be more nuns available to participate in future iterations of this research program. It will also be critical to examine lifestyle risk factors as well as social and cultural influences on monastics' experience of depression symptoms. Finally, this study raises critical issues related to the ethical obligations and best practices in conducting cross-cultural research at the intersection of mental health. While, again, we must interpret these data with care, they do highlight the potential importance of diagnostic and clinical resources made available to monastics. Preliminary evidence indicates that the T-PHQ-9 is a reliable instrument for these important future analyses.

\section{Declarations}

\section{Declarations}

Ethics approval and consent to participate: This study was conducted with approval from the Emory University Institutional Review Board (IRB00097591). All study participant provided informed consent prior to study participation.

Consent for publication: Not applicable

Availability of data and materials: The dataset used and analyzed in this study and the T-PHQ-9 are available from the corresponding author on reasonable request.

Competing interests: The authors declare that they have no competing interests

Funding: There was no funding for this study. 
Authors' contributions: JSM helped design the study, analysed and interpreted the data, and was a major contributor in writing the manuscript; DS helped design the study, helped administer surveys and enter data, and helped with data interpretation and writing the manuscript; TS translated the survey, helped administer surveys, and helped with data interpretation and writing the manuscript; $\mathrm{HC}$ helped enter data and helped writing the manuscript, JZ and AE were major contributors in designing the study and helped with interpretation and writing the manuscript. All authors read and approved the final manuscript

Acknowledgements: This project is indebted to His Holiness the Dalai Lama, who envisioned and supports, together with the Templeton Foundation and Joni Winston, the Emory Tibet Science Initiative. We are grateful to the translators for their expertise and assistance and to all of the monastics for their time and efforts in completing the survey.

\section{References}

1. Smith K, De Torres I. A world of depression. Nature. 2014;515.

2. Vos T, Abajobir AA, Abate KH, Abbafati C, Abbas KM, Abd-Allah F, et al. Global, regional, and national incidence, prevalence, and years lived with disability for 328 diseases and injuries for 195 countries, 1990-2016: a systematic analysis for the Global Burden of Disease Study 2016. The Lancet. 2017;390(10100):1211-59.

3. James SL, Abate D, Abate KH, Abay SM, Abbafati C, Abbasi N, et al. Global, regional, and national incidence, prevalence, and years lived with disability for 354 diseases and injuries for 195 countries and territories, 1990-2017: a systematic analysis for the Global Burden of Disease Study 2017. The Lancet. 2018;392(10159):1789-858.

4. Salleh MR. The Burden of Mental IIIness: An Emerging Global Disaster. Journal of Clinical Health Sciences. 2018;3(1):5-12.

5. 127935 Tibetans living outside Tibet. Tibetan survey. Hindustantimes. 2010 Dec 04, 2010.

6. Mills EJ, Singh S, Holtz TH, Chase RM, Dolma S, Santa-Barbara J, et al. Prevalence of mental disorders and torture among Tibetan refugees: A systematic review. BMC international health human rights. 2005;5(1):7.

7. Conway JS. The Tibetan community in exile. Pacific affairs. 1975:74-86.

8. Purohit K. After 60 years in India, why are Tibetans leaving? Aljazeera. 201921 Mar 2019.

9. Sonam T. Incubating Western Science Education in Tibetan Buddhist Monasteries in India. Science Education in India: Springer; 2019. p. 27-45.

10. Gray KM, Eisen A. The Emory-Tibet Science Initiative: Rethinking Cross-Cultural Science and Teaching. Journal of Microbiology \& Biology Education. 2019;20(1).

11. Chen W, Hall BJ, Ling L, Renzaho AM. Pre-migration and post-migration factors associated with mental health in humanitarian migrants in Australia and the moderation effect of post-migration stressors: findings from the first wave data of the BNLA cohort study. The Lancet Psychiatry. 2017;4(3):218-29. 
12. Fazel M, Wheeler J, Danesh J. Prevalence of serious mental disorder in 7000 refugees resettled in western countries: a systematic review. The Lancet. 2005;365(9467):1309-14.

13. Laban CJ, Komproe IH, Gernaat HB, de Jong JT. The impact of a long asylum procedure on quality of life, disability and physical health in Iraqi asylum seekers in the Netherlands. Social Psychiatry psychiatric epidemiology. 2008;43(7):507.

14. Jin Y, Kandula NR, Kanaya AM, Talegawkar SA. Vegetarian diet is inversely associated with prevalence of depression in middle-older aged South Asians in the United States. Ethnicity \& health. 2019:1-8.

15. Verma G, Araya R. The effect of meditation on psychological distress among buddhist monks and nuns. The International Journal of Psychiatry in Medicine. 2010;40(4):461-8.

16. Lewis SE. Trauma and the making of flexible minds in the Tibetan exile community. Ethos. 2013;41(3):313-36.

17. Holtz TH. Refugee trauma versus torture trauma: a retrospective controlled cohort study of Tibetan refugees. The journal of nervous mental disease. 1998;186(1):24-34.

18. Hussain D, Bhushan B. Posttraumatic growth experiences among Tibetan refugees: A qualitative investigation. Qualitative Research in Psychology. 2013;10(2):204-16.

19. Tam W, Lo K, Pacheco JJMe. Prevalence of depressive symptoms among medical students: overview of systematic reviews. 2019;53(4):345-54.

20. Kroenke K, Spitzer RL, Williams JB. The PHQ-9: validity of a brief depression severity measure. J Gen Intern Med. 2001;16(9):606-13.

21. Pfizer. Patient Health Questionnaire (PHQ-9) [Available from: http://www.phqscreeners.com.

22. Cameron IM, Crawford JR, Lawton K, Reid IC. Psychometric comparison of PHQ-9 and HADS for measuring depression severity in primary care. Br J Gen Pract. 2008;58(546):32-6.

23. Dadfar M, Kalibatseva Z. Lester DJTip, psychotherapy. Reliability and validity of the Farsi version of the Patient Health Questionnaire-9 (PHQ-9) with Iranian psychiatric outpatients. 2018;40(2):144-51.

24. Kocalevent R-D, Hinz A, Brähler E. Standardization of the depression screener patient health questionnaire (PHQ-9) in the general population. Gen Hosp Psychiatry. 2013;35(5):551-5.

25. Liu S-I, Yeh Z-T, Huang H-C, Sun F-J, Tjung J-J, Hwang L-C, et al. Validation of Patient Health Questionnaire for depression screening among primary care patients in Taiwan. Compr Psychiatr. 2011;52(1):96-101.

26. Elhai JD, Contractor AA, Tamburrino M, Fine TH, Prescott MR, Shirley E, et al. The factor structure of major depression symptoms: a test of four competing models using the Patient Health Questionnaire-9. 2012;199(3):169-73.

27. Krause JS, Reed KS. McArdle JJJAopm, rehabilitation. Factor structure and predictive validity of somatic and nonsomatic symptoms from the patient health questionnaire-9: a longitudinal study after spinal cord injury. 2010;91(8):1218-24. 
28. Guo B, Kaylor-Hughes C, Garland A, Nixon N, Sweeney T, Simpson S, et al. Factor structure and longitudinal measurement invariance of $\mathrm{PHQ}-9$ for specialist mental health care patients with persistent major depressive disorder. Exploratory Structural Equation Modelling. 2017;219:1-8.

29. Petersen JJ, Paulitsch MA, Hartig J, Mergenthal K, Gerlach FM, Gensichen JJJoad. Factor structure and measurement invariance of the Patient Health Questionnaire-9 for female and male primary care patients with major depression in Germany. 2015;170:138-42.

30. Wang W, Bian Q, Zhao Y, Li X, Wang W, Du J, et al. Reliability and validity of the Chinese version of the Patient Health Questionnaire (PHQ-9) in the general population. Gen Hosp Psychiatry. 2014;36(5):539-44.

31. Rancans E, Trapencieris M, Ivanovs R, Vrublevska J. Validity of the PHQ-9 and PHQ-2 to screen for depression in nationwide primary care population in Latvia. Annals of general psychiatry. 2018;17(1):33.

32. Kim YE, Lee B. The Psychometric Properties of the Patient Health Questionnaire-9 in a Sample of Korean University Students. Psychiatry Investigation. 2019;16(12):904.

33. Huang FY, Chung H, Kroenke K, Delucchi KL, Spitzer RL. Using the patient health questionnaire-9 to measure depression among racially and ethnically diverse primary care patients. J Gen Intern Med. 2006;21(6):547-52.

34. Lotrakul M, Sumrithe S, Saipanish R. Reliability and validity of the Thai version of the PHQ-9. BMC Psychiatry. 2008;8(1):46.

35. Kleinman A, Kleinman J. in Chinese Society among Culture, Depressive Experiences, and the Meanings of Pain. Culture and depression: Studies in the anthropology and cross-cultural psychiatry of affect and disorder. 1985;16:429.

36. Yen S, Robins CJ, Lin N. A cross-cultural comparison of depressive symptom manifestation: China and the United States. J Consult Clin Psychol. 2000;68(6):993.

37. Boiger M, Ceulemans E, De Leersnyder J, Uchida Y, Norasakkunkit V, Mesquita B. Beyond essentialism: Cultural differences in emotions revisited. Emotion. 2018;18(8):1142.

38. Kirmayer LJ. Cultural variations in the clinical presentation of depression and anxiety: implications for diagnosis and treatment. J Clin Psychiatry. 2001;62:22-30.

39. Kroenke K, Spitzer RL, Williams JB, Löwe B. The patient health questionnaire somatic, anxiety, and depressive symptom scales: a systematic review. Gen Hosp Psychiatry. 2010;32(4):345-59.

40. Brody DJ, Pratt LA, Hughes JP. Prevalence of depression among adults aged 20 and over: United States, 2013-2016: US Department of Health and Human Services, Centers for Disease Control and \&\#8230.

41. Johansson R, Carlbring P, Heedman $\AA$, Paxling B, Andersson G. Depression, anxiety and their comorbidity in the Swedish general population: point prevalence and the effect on health-related quality of life. PeerJ. 2013;1:e98.

42. Sobowale K, Zhou AN, Fan J, Liu N, Sherer RJljome. Depression and suicidal ideation in medical students in China: a call for wellness curricula. 2014;5:31. 
43. Yoon S, Lee Y, Han C, Pae C-U, Yoon H-K, Patkar AA, et al. Usefulness of the Patient Health Questionnaire-9 for Korean medical students. 2014;38(6):661-7.

44. Ngasa SN, Sama C-B, Dzekem BS, Nforchu KN, Tindong M, Aroke D, et al. Prevalence and factors associated with depression among medical students in Cameroon: a cross-sectional study. 2017;17(1):216.

45. Ibrahim AK, Kelly SJ, Adams CE, Glazebrook, CJJopr. A systematic review of studies of depression prevalence in university students. 2013;47(3):391-400.

46. Majidi M, Khadembashi N, Etemad K, Jafari M, Khodakarim SJIJoC, Health M. Associated factors with major depression: a path analysis on NHANES 2013-2014 study. 2018;11(4):763 - 73.

47. Li Z, Wang W, Xin X, Song X, Zhang DJJoad. Association of total zinc, iron, copper and selenium intakes with depression in the US adults. 2018;228:68-74.

48. Bauldry S. Variation in the protective effect of higher education against depression. Society mental health. 2015;5(2):145-61.

49. MaDDen D. Do schooling reforms improve long-term health? IZA World of Labor. 2016.

50. Wangmo T, Teaster PB. The bridge from then to now: Tibetan elders living in diaspora. Journal of Applied Gerontology. 2010;29(4):434-54.

51. Gearing RE, Alonzo D. Religion and suicide: New findings. Journal of religion health. 2018;57(6):2478-99.

52. Sachs E, Rosenfeld B, Lhewa D, Rasmussen A, Keller A. Entering exile: Trauma, mental health, and coping among Tibetan refugees arriving in Dharamsala, India. Journal of Traumatic Stress: Official Publication of The International Society for Traumatic Stress Studies. 2008;21(2):199-208.

53. Benedict AL, Mancini L, Grodin MA. Struggling to meditate: Contextualising integrated treatment of traumatised Tibetan refugee monks. Mental Health Religion Culture. 2009;12(5):485-99.

54. Willis GB. Cognitive interviewing: A tool for improving questionnaire design: Sage publications; 2004.

55. Eid RS, Gobinath AR, Galea LA. Sex differences in depression: Insights from clinical and preclinical studies. Progress in neurobiology. 2019.

\section{Figures}


-Anhedonia

-Depressed mood

-Sleep problems

- Low energy

-Appetite change

- Low self-esteem

- Concentration difficulties

-Psychomotor agitation

- Suicidal ideation

\section{Figure 1}

T-PHQ-9 item responses visualized as percent monastics endorsing each response option. 